\title{
ASYMPTOTIC FORMULAE ASSOCIATED WITH THE WALLIS POWER FUNCTION AND DIGAMMA FUNCTION
}

\author{
Chao-Ping Chen, Neven Elezović And LenKa VuKŠić
}

Abstract. Let $s, t$ be two given real numbers, $s \neq t$. We determine the coefficients $c_{j}(s, t)$ such that

$$
\left.\left[\frac{\Gamma(x+t)}{\Gamma(x+s)}\right]^{1 /(t-s)} \sim \exp \left(\psi\left(x+\sum_{j=0}^{\infty} c_{j}(s, t) x^{-j}\right)\right)\right)
$$

as $x \rightarrow \infty$, where $\psi(x)=\Gamma^{\prime}(x) / \Gamma(x)$ denotes the digamma function. Also, the analysis of the coefficients in the asymptotic expansion of the composition $\exp (\psi(x+s))$ is given in details.

Mathematics subject classification (2010): Primary 33B15; Secondary 41A60. expansions.

Keywords and phrases: Gamma function; digamma (psi) function; Bernoulli polynomials; Asymptotic

\section{REFERENCES}

[1] M. Abramowitz And I. A. Stegun (Editors), Handbook of Mathematical Functions with Formulas, Graphs, and Mathematical Tables, Applied Mathematics Series 55, Ninth printing, National Bureau of Standards, Washington, D.C., 1972.

[2] T. Burić AND N. ElEzović, Bernoulli polynomials and asymptotic expansions of the quotient of gamma functions, J. Comput. Appl. Math. 235 (2011), 3315-3331.

[3] T. BURIĆ AND N. ElEZOVIĆ, New asymptotic expansions of the quotient of gamma functions, Integral Transforms Spec. Funct. 23 (2012), 355-368.

[4] T. Burić, N. EleZoviĆ AND R. ŠIMIĆ, Asymptotic expansions of the multiple quotients of gamma functions and applications, Math. Inequal. Appl., to appear.

[5] C.-P. CHen, Monotonicity and convexity for the gamma function, J. Inequal. Pure Appl. Math. 6 (2005), no. 4, Article 100, 6 pp.

[6] C.-P. Chen And F. QI, The best bounds in Wallis' inequality, Proc. Amer. Math. Soc. 133 (2005), 397-401.

[7] N. Elezović, C. Giordano And J. PeČArić, The best bounds in Gautschi's inequalitity, Math. Inequal. Appl. 3 (2000), 239-252.

[8] N. Elezović AND J. PeČARIĆ, Differential and integral f-means and applications to digamma function, Math. Inequal. Appl. 3 (2000), 189-196.

[9] A. Erdélyi, Asymptotic expansions, Dover Publications, New York, 1956.

[10] W. GAUTSCHI, Some elementary inequalities relating to the gamme and incomplete gamma function, J. Math. Phys. 38 (1959), 77-81.

[11] H. W. Gould, Coefficient identities for powers of Taylor and Dirichlet series, Amer. Math. Monthly 85 (1978), 84-90.

[12] D. KeRshaW, Some extensions of W. Gautschi's inequalities for gamma function, Math. Comp. 41 (1983), 607-611.

[13] D. KERSHAW, Upper and lower bounds for a ratio involving the gamma function, Anal. Appl. (Singap.) 3 (2005), 293-295.

[14] Y. L. LuKe, The Special Functions and their Approximations, vol. I, Academic Press, New York, 1969. 
[15] M. Merkle, Logarithmic convexity and inequalities for the Gamma function, J. Math. Anal. Appl. 203 (1996), 369-380.

[16] F. QI, Bounds for the ratio of Two Gamma Functions, J. Inequal. Appl. 2010, Aticle ID 493058 (84 p), doi: $10.1155 / 2010 / 493058$

[17] F. QI, B.-N. Guo And C.-P. Chen, The best bounds in Gautschi-Kershaw inequalitities, Math. Inequal. Appl. 9 (2006), 427-436.

[18] F. G. Tricomi and A. Erdélyi, The asymptotic expansion of a ratio of Gamma functions, Pacific. J. Math, 1 (1951), 133-142. 